\title{
Present-day slip-rate of Altyn Tagh Fault: Numerical result constrained by GPS data
}

\author{
Xiong Xiong ${ }^{1,2,3}$, Pil-Ho Park ${ }^{3}$, Yong Zheng ${ }^{4}$, Houtze Hsu ${ }^{1}$, and Uk Han ${ }^{5}$ \\ ${ }^{1}$ Institute of Geodesy and Geophysics, Chinese Academy of Sciences, Wuhan 430077, China \\ ${ }^{2}$ Institute of Geology and Geophysics, Chinese Academy of Sciences, Beijing 100101, China \\ ${ }^{3}$ GPS Research Group, Korea Astronomy Observatory, Daejeon 305-348, South Korea \\ ${ }^{4}$ College of Earth and Space Sciences, University of Science and Technology of China, Hefei 230026, China \\ ${ }^{5}$ Department of Environmental Sciences, Korean Military Academy, Seoul 139-799, South Korea
}

(Received June 24, 2003; Revised August 26, 2003; Accepted August 26, 2003)

\begin{abstract}
Geological and seismic evidence suggests that nearly two thirds of the convergence between India and Eurasia is accommodated by the crustal deformation of Asia. Two competing mechanisms were proposed to describe this accommodation: distributed crustal thickening and lateral extrusion along main faults. The kinematics of the Altyn Tagh Fault (ATF) is critical in determining the relative importance of these two mechanisms, inasmuch as the ATF slip-rates predicted by hypotheses of these competing mechanisms are very different. Using a finite element formalism to construct a thin-sheet model, we seek a velocity solution approaching the current kinematics of the ATF. The GPS data in the Tibetan Plateau and neighboring regions are employed as constraint conditions, in successive steps. The predicted velocity distribution near the ATF fits well to the observations, with overall standard deviations of $2.3 \mathrm{~mm} / \mathrm{yr}$ and $2.8 \mathrm{~mm} / \mathrm{yr}$ for the northward and eastward components, respectively. The inferred average slip-rate of the ATF is $(7.4 \pm 1) \mathrm{mm} / \mathrm{yr}$, with some variation along the fault. The slip-rate estimate of the ATF reported in this paper supports the distributed crustal thickening hypothesis for the crustal deformation of the Tibetan Plateau.
\end{abstract}

Key words: Slip-rate, Altyn Tagh Fault, GPS observations, numerical simulation.

\section{Introduction}

The Altyn Tagh Fault (ATF), bounding the Tarim Basin to the north, and the Tibetan Plateau and Qaidam Basin to the south, is a left-lateral strike-slip fault extending at least 1600 $\mathrm{km}$ along the northern edge of the Tibetan Plateau (Fig. 1). Fieldwork confirms that the ATF is one of the largest and the most active faults in Asia, and it dominates the tectonics and Cenozoic structure of the northern Tibet (Yin and Harrison, 2000).

Geological studies suggest that at least $1400 \mathrm{~km}$ of the north-south crustal shortening induced by the northward drift of the continental India has been absorbed by the Tibetan Plateau since the onset of the Indo-Asian collision at about $50 \mathrm{Ma}$ (Yin and Harrison, 2000). Two dominant processes were proposed to absorb the crustal shortening: distributed crustal thickening and lateral extrusion (Yue et al., 2003). The distributed crustal thickening hypothesis outlines a process of crustal shortening and thickening, which is caused by the compressive north-south stresses generated by the converging plates, and is responsible for the high topography of the region (e.g., Houseman and England, 1993). At the same time, as originally proposed by Molnar and Tapponnier (1975), the lateral extrusion hypothesis suggests that some of the indentation of Asia by India has been accommodated by strike-slip deformation involving eastward displacement and

Copy right(C) The Society of Geomagnetism and Earth, Planetary and Space Sciences (SGEPSS); The Seismological Society of Japan; The Volcanological Society of Japan; The Geodetic Society of Japan; The Japanese Society for Planetary Sciences. rotation of large crustal blocks out of the collision zone along main faults (e.g., Avouac and Tapponnier, 1993; Peltzer et al., 1989; Tapponnier and Molnar, 1977; Tapponnier et al., 2001). Although the broad picture that the crustal shortening is absorbed by these two processes has been generally agreed upon by geoscientists, no consensus has been reached yet on the relative importance of these two processes, due to the lack of precise determination of the kinematics in the entire deformation zone.

These two hypotheses predict very different slip-rates of the ATF. While the lateral extrusion hypothesis predicts a high slip-rate of the ATF $(20-30 \mathrm{~mm} / \mathrm{yr})$ (e.g., Peltzer et al., 1989), the distributed crustal thickening hypothesis yields a much lower value $(<10 \mathrm{~mm} / \mathrm{yr})$ (e.g., Houseman and England, 1993). The lateral extrusion hypothesis has enjoyed widespread support from the large slip-rate (20-30 $\mathrm{mm} / \mathrm{yr}$ ) of the ATF derived by Landsat-image interpretation (e.g., Avouac and Tapponnier, 1993; Peltzer et al., 1989), as well as by fieldwork (e.g. Meriaux et al., 1998; Yue et al., 2001). However, the lower bounds of some geological slip-rate estimates ( $<10 \mathrm{~mm} / \mathrm{yr})$ (e.g., CSBS, 1992; Meyer et al., 1996) and GPS surveys (Bendick et al., 2000; Shen et al., 2001) are in favor of the prediction of the distributed thickening hypothesis. Therefore, the determination of the slip-rate of the ATF becomes a key feature in the debate between these two hypotheses, as well as in deciphering the mechanism responsible for the formation and evolution of the Tibetan Plateau.

Geodetic data, independent from geological observations, 


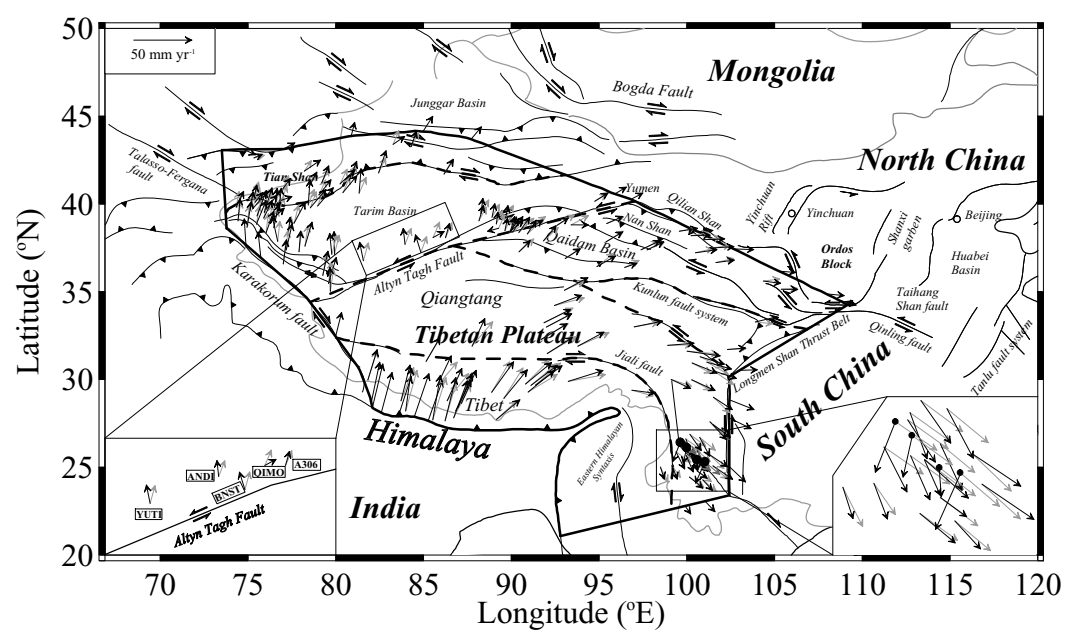

Fig. 1. GPS-measured (black arrows) and calculated velocities (gray arrows) in the Tibetan Plateau and neighboring regions, with a background schematic map of tectonics adapted from Yin and Harrison (2000). All the velocities are referenced to the stable Eurasia. The detailed map of the velocity distribution in the area near the western segment of the ATF is given in the lower left corner of the figure. The enlarged sketch map of the velocity distribution in eastern Tibet is shown in the lower right corner of the Figure. Four sites with anomaly GPS velocities are marked by dots (see text for details).

provide present-day constraints for these hypotheses, in the form of measurements of crustal movement, as well as estimates of slip-rate along faults. However, since the GPS surveys are confined within a narrow zone of the ATF (Bendick et al., 2000; Shen et al., 2001), the slip-rate is poorly defined in most parts of the ATF. The overall pattern of the sliprate along the entire fault is presently unavailable by geodetic studies.

Numerical experiments provide a powerful tool to predict velocities, stress and strain rates, by solving the equations of force balance and mass conservation with some assumed material properties. Assuming that the velocities of crustal movement are mechanically related to one another, and using a thin-sheet model supplemented by a finite-element technique, we predict, in this paper, the velocity distribution, and, furthermore, the slip-rate of the ATF as constrained by GPS data. The significance of the estimated slip-rate for the mechanism of crustal deformation of the Tibetan Plateau is also discussed.

\section{GPS Data}

In order to study the crustal deformation of China, several regional GPS networks were established in China and neighboring regions in the $1990 \mathrm{~s}$, by some Chinese national projects and international programs (e.g. Bendick et al., 2000; Shen et al., 2001). All raw data from regional GPS networks were merged to approach a self-consistent velocity field. Finally, a total of 354 solution velocities, delineating the crustal deformation pattern of the China continent, were compiled (Wang et al., 2001). Most velocity uncertainties are in the range of 1 to $4 \mathrm{~mm} / \mathrm{yr}$, with mean uncertainties of $2.2 \mathrm{~mm} / \mathrm{yr}$ and $2.4 \mathrm{~mm} / \mathrm{yr}$ for northward and eastward components, respectively.

In this study, 172 velocity data, selected from a GPS dataset (Wang et al., 2001), supplemented by 27 data reported by Shen et al. (2001), were used for studying the kinematics of the ATF. Excluding 6 sites common to both datasets, we finally employed a total of 193 GPS velocities in the Tibetan Plateau and neighboring areas. The velocity vectors, with respect to the stable Eurasia, are shown in Fig. 1.

\section{Model}

To determine the distributed velocity field and slip-rate of the ATF, we constructed a two-dimensional, elastic, thinsheet model covering the Tibetan Plateau and neighboring areas, as shown in Fig. 1. Although accurate mechanical parameters and crustal deformation should be represented in three dimensions, it is usually sufficient, as an approximation, to parameterize the velocity field in two dimensions by a thin-sheet model, which gives a critical reduction in computational cost and is widely applied (e.g., Bird, 1999). Because the crustal deformation investigated in this work is a short-term one ( $<10$ years), and is confined in the shallow portion, an elastic model is applicable (e.g., Peltzer and Saucier, 1996), although plastic deformation may be dominant in the active colliding orogene.

In Fig. 1, the studied area, which is shown enclosed by thick lines, with faults indicated by thick dashed lines, covers the labeled main tectonic units and faults. Since it is suggested that the geometry of tectonic units may substantially affect the pattern of crustal deformation (Jackson et al., 1995), we outlined the model by its real configuration, including blocks and faults. An elastic constitutive relation was employed for the tectonic units, each with individual mechanical parameters. The faults were introduced as discontinuities, which were modeled by contact pairs whose properties are defined by the normal stiffness, the tangential stiffness, and the coefficient of sliding friction (see chapter 10 of the Structural Analysis Guide Section, in the ANSYS HELP Menu of ANSYS, for details). Nodes belonging to a fault are split into two nodes, allowing elements on both sides of the fault to move in relation to one another. At fault intersections (triple junction), nodes are split into three nodes. The north-south normal faults distributed in southern Tibet were not taken into account, due to their small contri- 


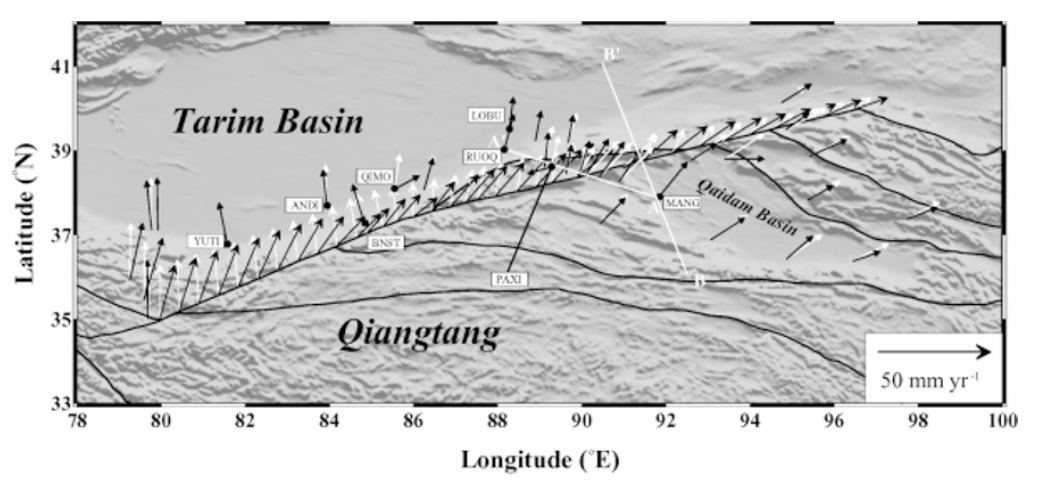

Fig. 2. Velocity distribution along the ATF. The black and white arrows with arrowheads indicate the calculated velocities at the nodes on the southern and northern sides of the ATF, respectively. The velocities at 37 GPS sites near the ATF are indicated by the black arrows with triangular heads, while the predicted velocities are represented by the white ones. The cross section $\mathrm{AA}^{\prime}$ roughly corresponds to the GPS survey line at the central segment of the ATF (Bendick et al., 2000). The line BB' corresponds the profile of Shen et al. (2001) (see Shen et al. (2001) for a detailed description of the profile). The GPS sites that are mentioned in the text are marked by black dots and labeled by site codes. For clarity, PAXI is specially indicated by a thick black line.

bution (Peltzer and Saucier, 1996).

The finite-element calculations were performed by ANSYS, a large-scale, multi-purpose, finite-element program developed by SAS IP, Inc. (USA) for solving several classes of engineering and scientific problems. The 2-D eight-node structure solid element PLANE82, which has large strain, large deflection and stress stiffening capability, was used to construct the solid continuum of the model (see chapter 12.6 of the ANSYS INC. Theory Reference, in the HELP Menu of ANSYS, for detailed description of the interpolation function). The faults were simulated by the element CONTACT48, a 2-D three-node point-to-surface contact element that is intended for general contact analysis in which the area of contact between two or more bodies is generally not known in advance (Ding et al., 2001). The studied area is modeled as a set of triangle elements.

\section{Numerical Results}

\subsection{Numerical strategy and process}

The principal idea for this work is based on the assumption that all the velocities or displacements in the studied area are intrinsically related in a mechanical way. Thus, if the mechanical principles governing crustal deformation and the relation among velocities are unveiled by constructing a model, we can infer or predict the velocities of unexplored regions by known GPS data.

We performed the numerical experiments in two successive steps. In the first step, 28 GPS data on the model sides were imposed as boundary conditions for modeling. No geodetic constraints were introduced within the interior of the studied area. Since the boundary of eastern Tibet near the Eastern Himalayan Syntaxis is not covered by GPS survey, we made an approximation whereby the velocities derived from NUVEL-1A, which is suggested to be in close agreement with GPS velocities (Argus and Heflin, 1995), were imposed as an alternative for the boundary conditions of this area. The calculated velocities at 165 interior sites, including 37 sites near the ATF, were subject to testing and fitting against the corresponding GPS-derived velocities. In the modeling, the values of the material parameters of tectonic blocks were determined initially by geophysical studies, and
Table 1. Mechanical parameters used in this study.

\begin{tabular}{lccc}
\hline Tectonic block & $\begin{array}{c}\text { Density } \rho \\
\left(\mathrm{kg} \mathrm{m}^{-3}\right)\end{array}$ & $\begin{array}{c}\text { Young's Modulus } E \\
(\mathrm{GPa})\end{array}$ & $\begin{array}{c}\text { Poisson's } \\
\text { ratio } v\end{array}$ \\
\hline Qiangtang & 2700 & 45 & 0.27 \\
Tarim Basin & 2800 & 85 & 0.27 \\
Tibet & 2700 & 65 & 0.27 \\
Other units & 2700 & 60 & 0.27 \\
\hline Faults & Normal Stiffness & Tangential Stiffness & Coefficient of \\
& $K_{n}(\mathrm{GPa} / \mathrm{m})$ & $K_{t}(\mathrm{GPa} / \mathrm{m})$ & sliding friction $\mu$ \\
\hline Altyn Tagh & 45 & 2 & 0.36 \\
Jiali & 50 & 1 & 0.3 \\
Other faults & 52 & 5 & 0.4 \\
\hline
\end{tabular}

were then adjusted within small ranges of variation. Since little geophysical evidence concerning the mechanical properties of the faults is available, their parameters were determined for general cases, and were then adjusted within their reasonable ranges to achieve the best consistency in the fit between the predicted and observed velocities.

After achieving the best fit in the first step, we tried to refine the model in a second step, in which the GPS velocities at 3 out of 37 sites near the ATF, (BNST, YUTI and LOBU (Figs. 1 and 2) (see next section for details)), and those at all the GPS sites in other regions, were introduced as further constraints. The GPS velocities at the other 34 sites near the ATF were subject to second-round testing and fitting, to refine the model. With the refined model from the second round of fitting to the GPS velocities at these 34 sites, we can then predict the velocity distribution along the ATF, provided an acceptable consistency between the calculated and observed velocities is achieved. The material parameters finally used in our modeling are listed in Table 1.

\subsection{Velocity distributed along the ATF}

Constrained by the boundary conditions, the calculated velocities at 165 GPS sites, along with the observed velocities, are shown in Fig. 1. The average standard deviations between the calculated and observed velocities are approximately $3.1 \mathrm{~mm} / \mathrm{yr}$ north $\left(\sigma_{N}\right)$ and $3.6 \mathrm{~mm} / \mathrm{yr}$ east $\left(\sigma_{E}\right)$, which are both less than the $2 \sigma$ uncertainties of the GPS observa- 

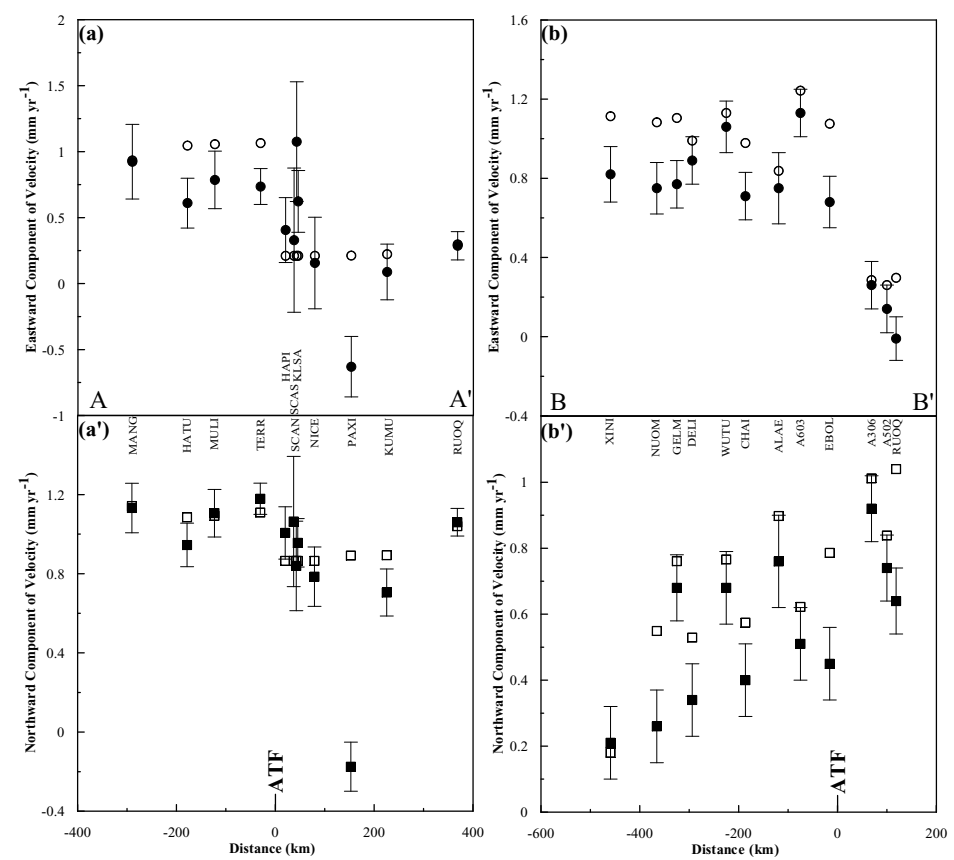

Fig. 3. Comparison of the calculated velocities with the GPS observations along two cross-sections of the ATF (Fig. 2): (a) and (a') for cross-section $\mathrm{AA}^{\prime}$ (Bendick et al., 2000), and (b) and ( $\mathrm{b}^{\prime}$ ) for $\mathrm{BB}^{\prime}$ (Shen et al., 2001). The filled circles and squares with error bars give the eastward and northward components of GPS velocities, respectively. The error bars represent the $1 \sigma$ uncertainties of the GPS velocities documented in Wang et al. (2001) and Shen et al. (2001). The blank circles and squares give the calculated results in this paper. The position of the ATF is set at 0 on the horizontal axis, and the positions of GPS sites in the figure are measured by their relative distance from the ATF.

tions (Wang et al., 2001). The best fit, with low standard deviations $\left(\sigma_{N}=1.6 \mathrm{~mm} / \mathrm{yr}\right.$ and $\left.\sigma_{E}=2.2 \mathrm{~mm} / \mathrm{yr}\right)$, is found in the Qaidam Basin. A good fit is obtained in the Tibet and Qiangtang, with $\sigma_{N}$ and $\sigma_{E}$ of $2.7 \mathrm{~mm} / \mathrm{yr}$ and $3.2 \mathrm{~mm} / \mathrm{yr}$, respectively. The calculated and GPS-measured velocities in the western Tarim Basin and Tien Shan, a region characterized by high seismicities, show a fairly good consistency, with standard deviations of $3.8 \mathrm{~mm} / \mathrm{yr}$ and $4.0 \mathrm{~mm} / \mathrm{yr}$ for the northward and eastward components, respectively. A relatively poor fit, with high standard deviations $\left(\sigma_{N}=3.3\right.$ $\mathrm{mm} / \mathrm{yr}$ and $\sigma_{E}=6.1 \mathrm{~mm} / \mathrm{yr}$ ) is found in the eastern Tibet, a well-known earthquake zone on the China continent. The discrepancy between the calculated and observed velocities of this area may be caused by the complicated crustal movements related to earthquakes. It should be pointed out that our model cannot predict the local anomalies because an assumption of a continuous medium is adopted, except at faults. In this work, we concentrated on the large-scale, overall pattern of the velocity distribution over the region, rather than on the local characteristics of individual anomaly velocities. Thus, if four sites (marked by dots in Fig. 1), whose velocities are quite different from the surrounding ones and may be caused by local effects related to earthquakes, are excluded, the fit is improved substantially $\left(\sigma_{N}=2.9 \mathrm{~mm} / \mathrm{yr}\right.$ and $\sigma_{E}=3.6 \mathrm{~mm} / \mathrm{yr}$ ). In addition, it was suggested, from many sets of numerical tests, that the resulting velocity pattern of this area has little influence on our target region, the ATF, due to the large separation between the eastern Tibet and the ATF.

The calculated velocities exhibit a good consistency with the GPS values near the ATF, except at the site PAXI, at which the velocity is quite different from those of neighbor- ing sites (see Fig. 2 for details), and is suggested to be a result of observation error (Bendick et al., 2000). The standard deviations, $\sigma_{N}$ and $\sigma_{E}$, are $2.9 \mathrm{~mm} / \mathrm{yr}$ and $4.3 \mathrm{~mm} / \mathrm{yr}$ for the average of all sites, and reduce to $2.4 \mathrm{~mm} / \mathrm{yr}$ and $3.9 \mathrm{~mm} / \mathrm{yr}$, respectively, if PAXI is excluded. However, we did not produce the local NNW motion of the Tarim Basin characterized by the velocities at sites BNST, YUTI and ANDI (Fig. 1), neither did Flesh et al. (2001) with a dynamic model. In the second step, for the purpose of refining the model, the GPS velocities of the sites BNST and YUTI, together with LOBU, were introduced as further constraints to represent the regional characteristics of the velocity field. The fit between the calculated velocities and the GPS values at the 34 GPS sites near the ATF was improved significantly, with low standard deviations $\left(\sigma_{N}=2.8 \mathrm{~mm} / \mathrm{yr}\right.$ and $\left.\sigma_{E}=3.3 \mathrm{~mm} / \mathrm{yr}\right)$. If PAXI is excluded, $\sigma_{N}$ and $\sigma_{E}$ reduce to $2.3 \mathrm{~mm} / \mathrm{yr}$ and 2.8 $\mathrm{mm} / \mathrm{yr}$, which are at the same level of uncertainties as those of the GPS velocities (Wang et al., 2001).

Figure 2 shows the comparison of the GPS-measured velocities with the calculated ones near the ATF, when constrained by the boundary and interior GPS velocities in the second step. The comparisons of the velocity components are shown in Fig. 3. It is clear that most calculated velocities fall within, or close to, the uncertainty ranges of the observations, except those at PAXI. Since a high consistency was achieved, the regional crustal deformation of the Tibetan Plateau and the ATF is believed to be represented by our model, from which we predicted the velocities at all nodes along the ATF, some of which are shown in Fig. 2.

\subsection{Slip-rate along the ATF}

The calculated results give the velocities/displacements of both sides of the ATF, from which we can evaluate the slip- 


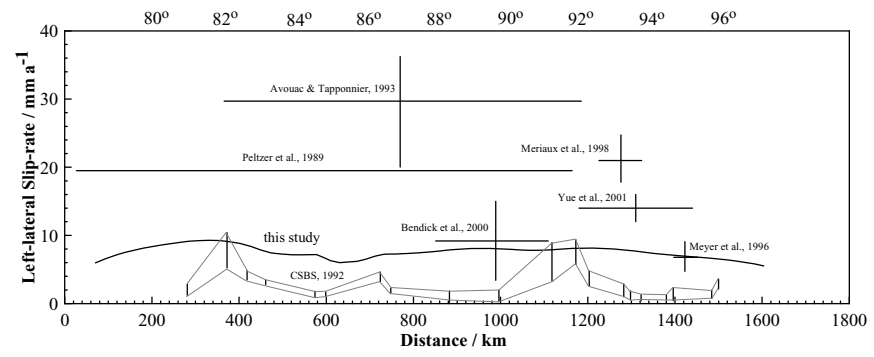

Fig. 4. The left-lateral slip-rate of the ATF predicted by this study, and the comparison with those derived from the indicated geological and geodetic studies (adapted from Bendick et al., 2000).

rate along the fault. We projected all the velocities along the fault, and deduced the slip-rate by comparing the components on two sides. The resulting slip-rate is shown in Fig. 4, along with the comparison with the results from other studies.

The averaged ATF slip-rate is approximately $(7.4 \pm 1)$ $\mathrm{mm} / \mathrm{yr}$. At a more detailed level, the estimates of slip-rate vary along the fault. The west end of the ATF is characterized by a low slip-rate around $5 \mathrm{~mm} / \mathrm{yr}$. In the west segment of the fault, the slip-rate reaches its maximum, $\sim 9.4 \mathrm{~mm} / \mathrm{yr}$, due to the relatively opposite motion between the two sides of the ATF, the Tarim Basin and Qiangtang. A decrease and small-scale variation of the slip-rate is found near the conjunction of the Tarim Basin, Qiangtang and the Qaidam Basin, where a complicated crustal deformation is expected. The central section of the fault is active, with a slip-rate estimated around $8 \mathrm{~mm} / \mathrm{yr}$. To the east, the slip-rate decreases gradually, to a value of less than $5 \mathrm{~mm} / \mathrm{yr}$ at the northeastern end of the ATF, which coincides with the geological results (Meyer et al., 1996). The calculated slip-rate is compatible with the value observed by the GPS survey across the central segment of the ATF (Bendick et al., 2000), and with the value inferred from some GPS measurements distributed in a broad region near the north segment of the ATF (Shen et al., 2001). However, our calculated slip-rate is about 2 to 3 times lower than the high values of geological estimates $(20 \sim 30 \mathrm{~mm} / \mathrm{yr})$, and the predicted slip-rate by the lateral extrusion hypothesis (e.g., Avouac and Tapponnier, 1993; Peltzer et al., 1989), although it is in close agreement with both the lower bound of the geological estimates ( $<10 \mathrm{~mm} / \mathrm{yr}$ ) (e.g., CSBS, 1992; Meyer et al., 1996), and the predicted value of the distributed crustal thickening hypothesis (e.g., Houseman and England, 1993).

\section{Discussion and Conclusions}

Although the significance of the exact slip-rate of the ATF, in revealing the mechanism for the crustal deformation in the Tibetan Plateau, has long been extensively acknowledged, the estimated values vary widely, ranging between millimeters and centimeters per year.

We have two groups of evidence relating to the ATF sliprate: geological and geodetic. Geological evidence represents the averaged kinematics over a period of geological time. Ideally, geological slip-rates of active faults are determined by dividing measured tectonic offsets by wellconstrained ages for the faulted geomorphic markers (Hetzel et al., 2002). Unfortunately, both of these quantities for the
ATF have not yet been well-defined, due to the uncertainties of determining the piercing points, and of geologically dating (Yin and Harrison, 2000). This is, we believe, the reason why the geological estimates of the ATF slip-rate differ greatly. Although the minimum is suggested to be $\sim 5$ $\mathrm{mm} / \mathrm{yr}$ (CSBS, 1992) and some low estimates are reported (e.g., Washburn et al., 2001; Yin et al., 1999), most geological studies, by several techniques, propose high slip-rates $(20 \sim 30 \mathrm{~mm} / \mathrm{yr})$ in the western and central parts of the ATF.

In contrast to the geological estimates, geodetic studies provide very precise independent constraints on the short time-scales ( $<10$ years) and current kinematics of the ATF. Since our model was constrained by GPS observations, it is clear that our results hold for the period of time spanned by the GPS surveys, which is approximately less than ten years.

With respect to the different time-scales, the geological estimates of the ATF slip-rates fall into two groups: the post-Oligocene/Miocene long-term slip-rates, which give average slip-rates over millions of years, and the late Quaternary ones, which are averaged over thousands of years. If both the high geological and the low geodetic slip-rates are correct and accurate within their uncertainties, the discrepancies between the present-day geodetic and most postOligocene/Miocene estimates suggest that the ATF slip-rate is strongly time-scale dependent (Yue et al., 2003). Also, this discrepancies imply a significant decrease of slip-rate from $20-30 \mathrm{~mm} / \mathrm{yr}$, over millions of years, to the presentday low values $(<10 \mathrm{~mm} / \mathrm{yr})$, although its mechanism still remains enigmatic. However, the discrepancy between the geodetic and the late Quaternary slip-rates is a puzzle, because it is difficult to imagine a mechanism responsible for the significant change (from $20-30$ to $\sim 5 \mathrm{~mm} /$ year) in sliprate within the last few thousands of years. This puzzle leads one to doubt the apparent magnitude of this discrepancy: either the late Quaternary slip-rates are overestimated, or the GPS ones underestimated, or both. If the GPS surveys measure interseismic crustal deformation only, and the shallow portion of the ATF is currently locked, the GPS-derived sliprates may be underestimated, and lower than the average over time. However, since both the GPS survey line (Bendick et al., 2000) and network (Shen et al., 2001), as well as cross-sections of our model, span several hundred kilometers across the fault, the low slip-rates obtained by the GPS observations and our simulation cannot be attributed to nearfault locking. Also, if earthquakes are responsible for the longer-term late Quaternary slip-rates, they must have occurred on the entire fault at a phenomenal rate over the past 
few thousand years (Shen et al., 2001). However, most of the ATF has not been ruptured for more than a century (Shen et al., 2001), and contemporary instrumental recordings reveal minor to medium levels of seismicity along the entire fault system (CSBS, 1992). The low late Quaternary slip-rates from palaeoseismological (Washburn et al., 2001) and geological (Yue et al., 2003) studies may imply an alternative explanation, that the high slip-rate (e.g., Peltzer et al., 1989) may be overestimated. A recent study (Hetzel et al., 2002), on cosmogenic nuclide dating and topographic surveying of terraces at the Yunmen thrust, demonstrates that the previous slip-rate estimates for main faults in Central Asia may be biased toward high values. An inference is logically derived, that the high Quaternary slip-rates are not well determined, and is far from conclusive. Intensive geological studies to precisely date the Quaternary slip-rate are expected.

Although our results on the ATF slip-rate are much lower than most geological estimates (both postOligocene/Miocene and late Quaternary), and do not support the prediction of the lateral extrusion hypothesis, it should be noted that the evolution processes of both the Tibetan Plateau and the ATF cannot be gleaned from our present-day snapshot of the kinematics. To answer questions concerning the entire evolutionary paths of the Tibetan Plateau, and to test the long-term role of the ATF in the Indo-Asia collision tectonics, one requires constraints on crustal movements over the entire period since the collision began, and determinations of the ATF slip-rate on various time-scales, from several years to several million years.

In spite of the time-scale limitation of the numerical results, we can, at least, draw the following inferences and conclusions:

1) According to our numerical modeling results, the present-day kinematics of the ATF is characterized by a relatively low slip-rate of $(7.4 \pm 1) \mathrm{mm} / \mathrm{yr}$, which supports the predictions of the distributed crustal thickening hypothesis concerning Asian deformation, and suggests that the ATF is currently less active.

2) Although we cannot rule out strike-slip faulting and lateral extrusion as a dominant mechanism for the crustal deformation of the Tibetan Plateau in its evolutionary history, the low slip-rate estimate of the ATF implies that the present-day crustal deformation of the plateau is principally characterized by distributed crustal shortening and thickening.

Acknowledgments. The authors thank André B. Fletcher (Korea Astronomy Observatory) for his help in the preparation and revision of the manuscript. We are grateful to Yongjun Yue (Stanford University) and Shoichi Yoshioka (Kyushu University) for their thoughtful comments and constructive suggestions, which led to a substantial improvement of the manuscript. This study was supported by the Chinese National Natural Science Foundation under grants 40274037 and 40234044, the Chinese Academy of Science under the award number of KZCX2-109, and partly by the Brain Pool Program sponsored by the KOFST.

\section{References}

Argus, D. F. and M. B. Heflin, Plate motion and crustal deformation estimated with geodetic data from the Global Positioning System, Geophys. Res. Lett., 22, 1973-1976, 1995.
Avouac, J. P. and P. Tapponnier, Kinematic model of active deformation in Central Asia, Geophys. Res. Lett., 20, 895-898, 1993.

Bendick, R., R. Bilham, J. Freymueller, K. Larson, and G. H. Yin, Geodetic evidence for a low slip rate in the Altyn Tagh fault system, Nature, 404, 69-72, 2000.

Bird, P., Thin-plate and thin-shell finite-element programs for forward dynamic modeling of plate deformation and faulting, Computers \& Geosciences, 25, 383-394, 1999.

CSBS (Chinese State Bureau of Seismology), The Altyn Tagh Active Fault System, Beijing: Seismology Publishing House, 319 pp., 1992.

Ding, Z. Y., Y. Q. Yang, Z. X. Yao, and G. H. Zhang, A thin-skinned collisional model for the Taiwan orogeny, Tectonophysics, 332, 321-331, 2001.

Flesh, L. M., A. J. Haines, and W. E. Holt, Dynamics of the India-Eurasia collision zone, J. Geophys. Res., 106(B8), 16435-16460, 2001.

Hetzel, R., S. Niedermann, M. X. Tao, P. W. Kubik, S. Ivy-Ochs, B. Gao, and M. R. Strecker, Low slip rates and long-term preservation of geomorphic features in Central Asia, Nature, 417, 428-432, 2002.

Houseman, G. and P. England, Crustal thickening versus lateral expulsion in the Indian-Asian continental collision, J. Geophys. Res., 98(B7), 1223312249, 1993.

Jackson, J., A. J. Haines, and W. E. Holt, The accommodation of ArabiaEurasia plate convergence in Iran, J. Geophys. Res., 100, 15205-15219, 1995.

Meriaux, A., P. Tapponnier, F. J. Ryerson, J. van der Woerd, C. Lasserre, X. W. Xu, R. Finkel, and M. Caffee, Large-scale strain patterns, great earthquake breaks, and late Pleistocene slip-rate along the Altyn Tagh Fault (China), EOS (Fall Meet. Suppl.), 79, 400, 1998.

Meyer, B., P. Tapponnier, Y. Guademer, G. Peltzer, S. M. Guo, and Z. T. Chen, Rate of left lateral movement along the easternmost segment of the Altyn Tagh fault, east of $96^{\circ} \mathrm{E}$ (China), Geophys. J. Int., 124, 29-44, 1996.

Molnar, P. and P. Tapponnier, Cenozoic tectonics of Asia: effects of a continental collision, Science, 189, 419-426, 1975.

Peltzer, G. and F. Saucier, Present-day kinematics of Asia derived from geological fault rates, J. Geophys. Res., 101(B12), 27943-27956, 1996.

Peltzer, G., P. Tapponnier, and R. Armijo, Magnitude of Late-Quaternary left-lateral displacements along the north edge of Tibet, Science, 246, 1285-1289, 1989

Shen, Z. K., M. Wang, Y. X. Li, D. D. Jackson, A. Yin, D. N. Dong, and P. Fang, Crustal deformation along the Altyn Tagh fault system, western China, from GPS, J. Geophys. Res., 106(B12), 30607-30621, 2001.

Tapponnier, P. and P. Molnar, Active faulting and tectonics of China, $J$. Geophys. Res., 82, 2905-2930, 1977.

Tapponnier, P., Z. Q. Xu, F. Roger, B. Meyer, N. Aenaud, G. Wittlinger, and J. S. Yang, Oblique stepwise rise and growth of the Tibetan Plateau, Science, 294, 1671-1677, 2001.

Wang, Q., P. Z. Zhang, J. T. Freymueller, R. Bilham, K. M. Larson, X. A. Lai, X. Z. You, Z. J. Niu, J. C. Wu, Y. X. Li, J. N. Liu, Z. Q. Yang, and Q. $Z$. Chen, Present-day crustal deformation in China constrained by Global Positioning System measurements, Science, 294, 574-577, 2001.

Washburn, Z., J. R. Arrowsmith, S. L. Forman, E. Cowgill, X. Wang, Y. Zhang, and Z. Chen, Late Holocene earthquake history of the central Altyn Tagh fault, China, Geology, 29(11), 1051-1054, 2001.

Yin, A. and T. M. Harrison, Geological evolution of the Himalayan-Tibetan Orogen, Annu. Rev. Earth Planet. Sci., 28, 211-80, 2000.

Yin, A., X. Wang, T. M. Harrison, E. Cowgill, P. Rumelhart, Z. Shen, D. Jackson, G. Gehrels, R. Butler, D. Roberson, G. Dupont-Nivet, R. Arrowsmith, and F. Ryerson, Preliminary results from a collaborative geologic investigation of the Altyn Tagh Fault, North Tibet. in 14th Himalaya-Karakorum-Tibet Workshop, Abstract volume, 185-86. Germany: Kloster Ettal, 1999

Yue, Y. J., B. D. Ritts, and S. A. Graham, Initiation and long-term slip history of the Altyn Tagh Fault, International Geology Review, 43, 1087 1093, 2001

Yue, Y. J., B. D. Ritts, S. A. Graham, J. L. Wooden, G. G. Gehrels, and Z. C. Zhang, Slowing extrusion tectonics: Lowered estimates of post-Early Miocene slip rate for the Altyn Tagh fault, Earth and Planet. Sci. Lett., 2003 (in press).

X. Xiong (e-mail: xxiong@asch.whigg.ac.cn), P.-H. Park, Y. Zheng, H. Hsu, and U. Han 